\title{
From Carmageddon and Invizimals to SimCity and Digimon: Blending Patterns in Videogame Titles ${ }^{1}$
}

\author{
Paula López Rúa
}

\begin{abstract}
This paper delves into the structure and motivations of blending by reporting on the results of the analysis of a corpus of 80 blends gathered from the field of videogaming. The starting point will be a multidimensional description based on a set of parameters and values drawn on previous works by, among others, Kemmer (2003), Ronneberger-Sibold (2006) and Mattiello (2013). In accordance with the principles of Prototype Theory (Lakoff 1987; Langacker 1987), the combination of values displayed by the items results in an overall degree of typicality and will allow their location in the centre or the periphery of the category. The theoretical framework will be put into practice in the analysis of a corpus of blends naming videogames. Most of them are found to be prototypical items, the most common type being the so-called "overlapping" blend (Splatoon: splat + platoon). Lastly, concerning the motivations for the creation of blends in this particular field, these items succeed in economically capturing key features of the game so as to awaken the interest of potential buyers. Moreover, blends anticipate the humorous, puzzling or creative qualities of the game they name and wink at the players' inventiveness to work out rules.
\end{abstract}

Keywords: blend, creativity, prototypes, typicality, videogames.

\section{[es] De Carmageddon e Invizimals a SimCity y Digimon: Patrones de cruces léxicos en títulos de videojuegos}

Resumen. Este trabajo profundiza en la estructura y motivaciones de los cruces léxicos a partir de los resultados del análisis de un corpus de 80 cruces léxicos del campo de los videojuegos. El punto de partida es una descripción multidimensional basada en un conjunto de parámetros recogidos de estudios previos de, entre otros, Kemmer (2003), Ronneberger-Sibold (2006) y Mattiello (2013). De acuerdo con los principios de la Teoría de Prototipos (Lakoff 1987; Langacker 1987), la combinación de valores exhibidos por los ítems da como resultado un nivel global de tipicidad, lo que permite su localización en el centro o la periferia de la categoría. El marco teórico se lleva a la práctica en el análisis de un corpus de cruces léxicos de nombres de videojuegos. La mayor parte de ellos resultan ser elementos prototípicos, y el tipo más común es el denominado cruce léxico "solapado" (Splatoon: splat + platoon $)$. Por último, en lo concerniente a las motivaciones para la creación de cruces léxicos en este campo, dichas formaciones capturan de manera efectiva y económica rasgos clave del juego para despertar el interés de compradores potenciales. Además, los cruces léxicos anticipan los rasgos humorísticos, intrigantes y creativos del juego al que nombran, al tiempo que hacen un guiño a la inventiva de los jugadores para descubrir las reglas.

Palabras clave: creatividad, cruce léxico, prototipos, tipicidad, videojuegos.

$1 \quad$ Research funded by the Spanish Ministry of Economy and Competitiveness, ERDF Funds and Xunta de Galicia (FFI2015-64057-P, ED431D 2017/09, ED431B 2018/05). These grants are hereby gratefully acknowledged.

2 Department of English Studies, University of Santiago de Compostela, paula.lopez@usc.es. 
Contents. 1. Introduction. 2. Theoretical framework. 2.1. Blends \& Co.: a parameter-based description of shortenings. 2.2. Features of prototypical blends (brunch, motel) and degrees of typicality. 3. Corpus analysis. 3.1. Prototypical and central cases. 3.2. Peripheral cases (20 items): complex clippings. 3.3. Graphic summary. 4. Motivations. 4.1. Pragmatic aims. 4.2. Ludic aims. 4.3. Anticipatory or introductory aims. 4.4. Group-binding aims. 4.5. Artistic aims. 5. Conclusion. 6. References. 6.1. Main references. 6.2. Electronic references used to compile the corpus.

How to cite this article: López Rúa, P. (2019) From Carmageddon and Invizimals to SimCity and Digimon: Blending Patterns in Videogame Titles, in Complutense Journal of English Studies 27, 183-204.

\section{Introduction}

The following paper delves into the patterns and motivations for blending by reporting on the results of a multidimensional analysis of a corpus of blends gathered from the field of videogaming. After introducing a parameter-based description of simple and complex shortenings developed under the premises of Prototype Theory, we will verify how this description applies to prototypical, central and peripheral cases of blends, and exemplify the centre-periphery structure of the category with items belonging to a subcorpus of blends selected from a larger corpus of videogame titles. Lastly, we will explore the possible motivations for the creation of blends in this particular field.

Concerning the object of study, videogames are difficult to define because, as Newman (2004: 8) observes, there is a great variety of game types which come under the broad umbrellas "videogames", "computer games" or "interactive entertainment". For the purpose of the linguistic analysis of game names put forward here we will adopt the broad definition of videogame offered by Tejeiro \& Pelegrina (2003: 20). These authors define videogames as electronic games with essentially ludic aims which allow real-time interaction between the player and the machine and which are basically dependent on a visual support such as a console, a PC or a TV. This definition basically agrees with that provided by Frasca (2001: 4), who also considers the social side of these games: they are "any form of computer-based entertainment software, either textual or image-based, using any electronic platform such as personal computers or consoles and involving one or multiple players in a physical or networked environment".

But why choose videogames as an object of study? To begin with, they are a form of entertainment of increasing social, cultural and economic importance in the 21st century. In recent years, videogames have evolved so as to appeal to users of all ages. Besides, they have managed to go beyond mere entertainment, since they can be used for education, socializing, and also to satisfy social demands (they may call attention on the need for social changes or promote fights against injustice). Moreover, they are also used to display artistic work (Gil Juárez 2007), as they have become "important art forms" which deserve a place in media and cultural studies (Newman 2004: 3). Videogames are hybrid art forms combining "elements from narrative fiction, film, music and sports" (Smuts 2005: para. 10). As such, their linguistic features also seem to deserve scholarly attention.

As will be shown in the sections that follow, this paper intends to address the feasibility of using the tools provided by Prototype Theory for the description of a 
minor category of word-formation devices, namely blends, in the above-mentioned field.

\section{Theoretical framework}

\subsection{Blends \& Co.: a parameter-based description of shortenings}

The starting point for the account of blends offered in this paper will be a multidimensional description based on a set of parameters and values drawn on López-Rúa $(2002,2004)$. This description will be resorted to for the account of both simple shortenings (clippings ${ }^{3}: l a b$ ) and complex shortenings (blends: motel, and initialisms $\mathrm{s}^{4}$ : laser), which are regarded as prototypical categories ${ }^{5}$. As a theory of categorization, Prototype Theory arises from contributions by cognitive psychology - Rosch (1978) - and linguistic anthropology - Berlin and Kay (1969). When transferred to linguistics, it became particularly useful in cognitive semantics, and prototypes and prototypical effects have been invoked to help the interpretation of metaphors (Gibbs and Steen 1997, Kövecses 2015). However, it has also been successfully applied to the description of phonological, morphological, lexical and syntactic categories (López-Rúa 2000). Prototypical categories are organized around prototypes or best examples, and their members display different degrees of typicality and fuzzy boundaries with respect to neighbouring categories. The combination of values exhibited by the items results in an overall degree of typicality and allows their location in the centre or the periphery of each of the categories considered. In accordance with the principles of Prototype Theory, if an item does not display a typical value, it is not excluded from the category (as happens in discrete categorization) but simply becomes a less central member. As will be shown in this paper, the items of the category under study can be arranged into a radial model as originally devised by Lakoff (1987). This radial model of categorization combines the node-link structure of networks with prototype effects and Wittgenstein's (1989) notion of family resemblance, which allows the incorporation of items which do not share features with the prototype but with other instances of the category which function as secondary centres. Lakoff applies the radial model to the description of categories like "mother", "anger", "noun", "verb" or the preposition "over". In radial categories with secondary centres, prototypes function as basic points of reference to assimilate other members to the category, but other items act as subcentres to allow the assimilation of more peripheral instances.

The parameters and values adopted for the description of shortenings will be the following:

1. Number and morphosyntactic type of source: one or more; a word, a phrase, or a sentence (as in the acronym ${ }^{6}$ WYSIWYG: 'What You See Is What You Get').

\footnotetext{
"Clipping is the process of shortening a word without changing its meaning or part of speech" (Bauer 1988: 33).

4 A superordinate category of items built out of the initial letters of the words in a phrase (alphabetisms and acronyms) (López-Rúa 2002).

5 For an account of prototypical categories in linguistics, see for example Lakoff (1987), Langacker (1987), Tsohatzidis (1990), Taylor (1995), and López-Rúa (2003).

6 An item built out of initials and read out as an ordinary word (López-Rúa 2002).
} 
2. Pronunciation of the resulting sequence: unexpanded (ordinary word or letter names, the latter being a typical value of alphabetisms ${ }^{7}$ ), or expanded (whole source, a typical value of written abbreviations, for example, $\mathrm{Mr}$ ).

3. Spelling: capitals (a typical value of alphabetisms and some acronyms), lower case or a combination (as in SoHo: 'South of Houston Street').

4. Degree of shortening. Maximum shortening is illustrated by initialisms: typically, they maintain one letter of each source word, or occasionally two in order to ease orthoepic pronunciation. In medium shortening, splinters are retained, that is, parts of morphemes which are not "independent formatives" (Lehrer 1996: 361). Splinters tend to be syllables or larger than syllables in their sources, since they are "intended to be recognized as belonging to a target word" (Lehrer 1996: 361), but when they are smaller, they tend to be parts of syllables: the onset, the onset and the nucleus, or the rhyme. Lastly, in minimum shortening, only one letter of a source word is deleted, as in the word 'slum' in the blend slurb (slu(m) + (sub)urb).

5. Degree of phonic integration of the constituents: sound intersection or overlap, as in sexploitation; sound union (the constituents form syllables, as in brunch: br(eakfast) + (l)unch, or orthoepically pronounceable sequences in acronyms such as laser); sound clustering (the constituents are stuck together and form different syllables), for example camcorder (camera + recorder), or $B B C$ ('British Broadcasting Corporation').

6. The parameter of the mode of expression considered by López-Rúa (2002, 2004) is left aside because it is devised to account for written abbreviations and their borderline cases with other categories, which fall beyond the scope of the present paper. Instead, a new parameter is added, namely the pattern of shortening, or the part of the original constituent that is shortened. Initialisms typically reduce the words of a phrase to initials, so they undergo final shortening (Aids). Clippings prototypically exhibit final shortening (lab), and less frequent but central patterns are initial shortening (varsity) and discontinuous shortening (initial + final, as in $f u$, from '(in)flu(enza)'). In order to ease the retrieval of the sources, blends typically undergo final + initial shortening, as in smog: smo(ke) + (f)og. As Gries (2004a: 416) explains, "usually, at least, the fore part of the first source word (sw1) is combined with the hind part of the second source word (sw2)". This agrees with the universal principle of perceptual salience, according to which "the beginning and the end of a word are more salient than what comes in between" (Mattiello 2013: 24).

\subsection{Features of prototypical blends (brunch, motel) and degrees of typicality}

This section opens with a comparison of definitions of blends provided by different authors. Definitions intend to encompass the majority of cases in a brief and simple way, and they mainly account for typical instances. Thus, for instance, Algeo (1991: 11) describes blending as a process of "simultaneously combining and shortening", and a blend as "a word made by joining two or more forms but omitting at least part of one". A similar definition is provided by Lehrer (2007), who also considers the existence of blends built out of more than two source words: "Blends are underlying

Items built out of initials and read out letter by letter, as in $B B C$ (López-Rúa 2002). 
compounds which are composed of one word and part of another, or parts of two (and occasionally three) other words" (Lehrer 2007: 116). Gries (2004b) adds the feature of overlapping material: "Blending involves the coinage of a new lexeme by fusing parts of at least two other source words of which either one is shortened in the fusion and/or where there is some form of phonemic or graphemic overlap of the source words" (2004b: 639). The different types of fusion which may be undergone by the constituents of a blend had already been noted by Kelly (1998: 579): typical blends are formed by "snipping components together either through simple concatenation or through concatenation coupled with overlap of shared phonological segments". Kelly (1998) also notes that splinters tend to be cut at phonological boundaries (e.g. syllable boundaries) or morphological ones (e.g. base + suffix). As shown in the definitions by Gries and Kelly, in the account of blends it is useful to keep in mind their prosodic quality. According to Plag (2003: 121), "blends are a class of complex words whose formation is best described in terms of prosodic categories", which implies an interaction of morphology and phonology.

In his corpus analysis of English blends, Cannon (1986) comments on their complex nature and concludes that

the numerous patterns that they exhibit are too diverse to be generated within the traditional framework of generative rules (...) Such rules would be rendered even more complex because of the occasional near-blurring between blends and derivations and compounds. (...) [Blending] shows the extreme difficulty in devising a taxonomy of absolutely discrete categories (Cannon 1986: 748-749).

In the light of the great variety of items subsumed under the category, it seems accurate to regard blends as a prototypical category with fuzzy boundaries, also in accordance with Bauer's (2012) remark:

We seem to have not cut-and-dried categories, but prototypical or canonical categories. So we expect to find not criteria that say that something is or is not a blend, but defeasible constraints, which may or may not be met in individual cases. This in fact gives us a very good approach to what we know about blends (Bauer 2012: 11-12).

\subsubsection{Application of parameters to prototypical cases}

The parameters and values introduced in subsection 2.1. apply to prototypical cases of blends as follows:

1. Number and morphosyntactic type of source: Two source words (blends with three source words are uncommon and not prototypical: Japornimation (Japan + porn + animation, an example drawn from Mattiello 2013: 307). The source words may form a phrase (wintertaintment: winter + entertainment) or not (dramedy: drama + comedy). Some authors, such as Dressler (2000) or Plag (2003) exclude the former subtype from the category. Dressler (2000: 5) calls them "syntagmatic shortenings" and Plag (2003: 122) "abbreviated compounds".

2. Pronunciation of the resulting sequence: unexpanded orthoepic pronunciation. 
3. Spelling: mainly lower case (when they are names of products, the first letter tends to be capitalized), as in Lipfinity: lipstick + infinity, "a Max Factor lipstick brand, guaranteed to last" (Mattiello 2013: 118).

4. Degree of shortening: the source words may exhibit different degrees of shortening, from maximum (only one or two letters remain: $<$ br- $>$ from 'breakfast' in brunch) to medium (splinters remain: <-medy> from 'comedy' in drame$d y$ ), or minimum (only one or two letters are deleted, as in $<1->$ from 'lunch' in brunch), provided that at least one of the source words is shortened to some extent, and that both source words do not undergo maximum shortening, since that is a typical combination of initialisms ( $U N$ : 'United Nations'). In the cases where two words overlap and are both retained in the resulting blend, the shortening can be applied to the first or to the second source word: thus slanguage can be analysed as: slang + (lang)uage (no shortening plus medium shortening), or as s(lang) + language (maximum shortening plus no shortening). Ronneberger-Sibold (2006) calls this type of blends "telescope blends" and describes them as items where "the blended lexemes are juxtaposed (...) but the end of the first overlaps with the beginning of the second" (2006: 161), as in Kamelefant.

5. Degree of phonic integration of the constituents: prototypical blends exhibit high to medium integration: intersection (palimony: (p)al + alimony) or union (brunch). Mattiello (2013: 134) notes that one of the regularities of blend formation is the tendency towards "similarity/identity at the juncture", and Kemmer (2003) mentions as a common characteristic of blends the fact that the sources share phonological material: this means that typical blends tend to display overlapping phonemes from the sources (occasionally the overlap is only graphic, as in smog, where the sound / $\mathrm{p} /$ comes from 'fog' whereas the letter $<_{0}>$ belongs to both 'smoke' and 'fog'). In cases of medium integration, splinters from different sources come together to form a new syllable, as in geep: $\mathrm{g}($ oat $)+(\mathrm{sh})$ eep, or Brexit: $\mathrm{Br}($ itish $)+$ exit.

6. Part of the constituent shortened (shortening pattern): blends prototypically undergo final + initial shortening, as noted by Plag (2003: 123), for example, $\mathrm{g}($ oat $)+(\mathrm{sh})$ eep $\rightarrow$ geep. Therefore, $\mathrm{AB}+\mathrm{CD} \rightarrow \mathrm{AD}$ according to Plag's rule (2003: 123). As Gries (2004b: 645) explains, "usually, blends result from a juxtaposition of the beginning of the first source word and the end of the second source word (with or without graphemic and/or phonemic overlap)".

7. Blends of overlapping words allow two simultaneous analyses; for example, sexploitation: word + final splinter with initial shortening (sex + (ex)ploitation), and initial splinter with final shortening + word (s(ex) + exploitation).

8. Central values concerning shortening patterns are also only initial shortening (word + final splinter), as in carbecue (car + (bar)becue) and floordrobe (floor + (war)drobe), and only final shortening (initial splinter + word), as in robomb (ro(bot) + bomb). Mattiello (2013: 120) calls them "partial blends".

An auxiliary parameter which can help to refine the internal structure of the category is the prosodic trace of one of the source words (prototypically the semantic head) in the new blend, measured in terms of length, stress, syllable structure and similarity of sounds. This parameter is based on observations made by several authors. For example, in Cannon's (1986) corpus analysis, the author notes that "each of our 
items almost always retains the same stress that occurs on one of its source words (...) and it is usually limited to (...) the maximum number of syllables in its longer source word" (1986: 741). A few counterexamples of the last statement can be found in Mattiello (2013), for instance fantabulous (fantastic + fabulous) and psychedelicatessen (psychedelic + delicatessen).

Plag's (2003) rule related to the size of the resulting blend is still more rigid: the blend tends to have "the size of the second element" (2003: 123). This generalization does not always hold true, since, as Mattiello (2013) notes, there are blends whose length is determined by the first source word (narcoma: narcotic + coma).

In spite of the counterexamples spotted, Mattiello (2013) lists the features "Conformity with the source words as regards stress" and "Conformity with the source words as regards length" as "more or less confirmable regularities in blend formation" (2013: 131-132). She also lists a set of criteria of well-formedness for blends, including prominence and salience. Prominence states that one of the constituents of the blend functions as the matrix, providing length, stress, and in the headed type, position (right-hand side) and meaning. The notion of matrix word is also used by Ronneberger-Sibold (2006) when she discusses "contour blending": the matrix word "provides the rhyme and the overall rhythmic contour of the blend (i.e. its number of syllables and its main stress)" (2006: 168).

In view of the features displayed by the majority of cases, it is possible to talk about two general tendencies as regards the prosodic features of blends, namely prototypical blends tend to carry stress in the same position as one of the sources and they tend to have the same number of syllables as one of the sources. That source is typically the semantic head in headed blends, which is located on the right-hand side.

Keeping in mind those general tendencies, if the union of constituents results in an item which inherits the length in number of syllables and the stress pattern of one of the original expanded constituents (often the right-hand element, which in headed blends acts as the head), this contributes to internal cohesion and makes the blend more central. Additionally, if there is sound clustering of constituents in the blend (and therefore low integration) but the component in the blend shares all or part of the syllabic structure (for example CV) with the replaced splinter of the source word, even displaying similar or identical sounds, this could also be taken as a sign of some internal cohesion which provides the blend with more centrality. The auxiliary features related to length and similarity of syllable structure are noted by Kemmer (2003) when she states that

it seems that similarity of syllable structure (...) is a factor in the felicity or likelihood of a blend: the resulting blend tends to share such overall structure with one or both of its source words. (...) For example, dumbsizing is a good blend because it echoes not only the $d$ and final nasal of $d o w n$, but also its CVC syllabic structure; moreover, the resulting blend is identical in syllable structure to one of the sourcewords, downsizing (Kemmer 2003: 74).

Consider the following examples: in soundsational (sound + (sen)sational) the prosodic trace of the source word 'sensational' (the semantic head) is displayed in the number of syllables and stress pattern of soundsational. Besides, the common phonemes $/ \mathrm{s} /$ and $/ \mathrm{n} /$ of the replaced splinter $<$ sen- $>/$ sen/ and $<$ sound- $>/$ saund/ occur in the new blend, and sound overlap increases typicality (see discontinuous overlap in subsection 3.1.1.). In breathalyser (breath + (an)alyser) constituents are clustered 
and form independent syllables in the new blend so the degree of phonic integration is low. However, there is still some internal cohesion and therefore centrality because the blend at least maintains the number of syllables and stress pattern of the semantic head 'analyser'.

\subsubsection{Degrees of typicality}

Considering the list of parameters and typical values explained in the previous subsection, blends display particular combinations of values with respect to those parameters. The values adopted by the items concerning each of the parameters are added up and result in an overall degree of typicality for each item. Consider the following examples of more or less central blends (parentheses are used to indicate deleted material from the source in the new item):

a) Example of a prototypical item: motel /məu 'tel/ (mot(or) + (h)otel). Values: two source words, lower case spelling, orthoepic pronunciation, medium + maximum shortening, high integration (sound overlap), typical pattern of shortening (final + initial) and features of the prosodic trace of one of the sources: the blend keeps the primary stress of 'hotel' (the right-hand word source) and the number of syllables of both sources, and the new syllable of the blend $<$ mo- $>$ keeps the syllabic structure of $<$ ho- $>/ \mathrm{CV} /$ and the same vowel sound /ou/ added to overlapping / $/$ /

b) Example of a central (but non-prototypical) item: modem / $\langle\operatorname{mou} \mathrm{dem} /(\bmod (\mathrm{u}-$ lator) + dem(odulator)). Values: two source words, lower case spelling, orthoepic pronunciation, medium + medium shortening, high integration $(<\mathrm{d}>$ sound overlap). The item exhibits an atypical pattern of shortening for blends: final + final. Additionally, concerning the prosodic trace of one of the sources, modem keeps the stress of 'modulator' (which is the left-hand constituent) but not the number of syllables or any other features. On the whole, and in view of the values displayed, the item is not prototypical, but still central.

c) Example of a peripheral item: Fortran /'fo: træn/ (for(mula) tran(slation), 'a computer programming language'). Values: two source words possibly forming a phrase, lower case spelling with a capital letter (although it was initially written all in capitals, which is a possible spelling of some initialisms), orthoepic pronunciation, medium + medium shortening, low integration (clustering), and the pattern of shortening is also final + final. In addition, Fortran keeps the stress of 'formula' (the left-hand constituent) but not its number of syllables or any other prosodic similarities. The item can be regarded as a complex clipping, a peripheral subgroup of items with points in common with blends, compounds, clippings and initialisms (see subsection 3.2).

d) Another example of a peripheral item is biopic /'bai əu pIk/ (bio(graphical) (motion) pic(ture): 'a biographical film'). Values: two or three source words forming a phrase (note that 'motion /moving picture' has been shortened to 'picture' and pic is an already existing clipping of 'picture'), lower case spelling, orthoepic pronunciation, medium + medium shortening, low integration of constituents (clustering), and the shortening pattern is also the atypical combination final + final. Concerning the prosodic trace, biopic carries stress on the first syllable, which is not the one carrying the main stress in 'bio- 
graphical' (the left-hand word source), and does not adjust to the number of syllables of any of the sources. Also, the replaced splinter <-graph-> /CCVC/ which continues $<$ bio- $>$ in the source 'biographical' does not share the syllabic structure or display similar phonemes with respect to $<$ pic- $>/ \mathrm{CVC} /$, the splinter which continues $<$ bio- $>$ in the blend. This item could also be classified as a complex clipping.

e) Finally, an example of a peripheral item sharing features with the neighbouring category of initialisms would be ADCONSEN: '(with) ad(vice and) consen(t of the) Sen(ate)', /'æd kpn , sen/. Values: seven source words forming one phrase (a source phrase of more than two words is a typical value of initialisms), upper case spelling (one possible spelling of initialisms), orthoepic pronunciation (a value for typical blends but also typical acronyms), medium + minimum + medium shortening of the constituents, and a combination of low integration (clustering) + possibly high integration in the splinter $<$ SEN $>$, from both 'consent' and 'Senate'. Prepositions and articles are also omitted (while in initialisms they can be partially kept: USofA vs. USA, COD $\leftarrow$ Cash On Delivery). ADCONSEN does not keep the primary stress or the number of syllables of any of the shortened constituents, and the pattern of shortening is not typical of blends $(f i n a l+$ final + final $)$.

\section{Corpus analysis}

The theoretical framework presented in the previous section will be illustrated by the analysis of a subcorpus of 80 blends taken from a larger corpus of 290 items which exemplify lexical innovation in videogame titles. The larger corpus comprises examples of affixation (Undertale, Fishdom), compounding (Chromagun, BoxBoy), and shortening (clipping: Sims; blending: Nintendogs; and initialization: N.O.V.A. 'Near Orbit Vanguard Alliance'). The corpus consists of titles of games released between 2000 and 2019. The titles were manually retrieved from a selection of relevant electronic references in the field of videogaming (see subsection 6.2.), which provided lists of games from which the items of the corpus were gathered. All the examples that were found were included in the study. The corpus includes new versions of games originally launched before 2000 (for example, Carmageddon). Only titles of videogames which are not based on previous films, books or TV programmes were included (thus, for example, items like Animaniacs or Sharknado were not considered).

As regards the semantic relationships of the constituents, the blends of the corpus were classified into three groups:

a) 55 headed blends (Lehrer's (2007) "syntactic compounds", Bauer's (2012) "determinative blends", Mattiello's (2013) "attributive blends"): the last source word is the semantic head and the first acts as a modifier, as in Carmageddon (car + Armageddon, a violent vehicular combat game), and Creativerse (creative + universe, a game which takes place in a world of blocks). The original constituents are therefore in a syntagmatic relationship.

b) 13 "coordinate blends": the same term is used by Bauer (2012) and Mattiello (2013). They are also called "copulative" or "coordinate" compounds by Lehrer (2007). They denote "semantic elements from both entities" (Lehrer 
2007: 119): for example, Wizorb (wizard + orb, a game where the player is a wizard who can transform into an orb), and Nihilumbra (nihilum + penumbra, a game in which the protagonist is created out of nothingness). In this case, the original constituents are in a paradigmatic relationship (Dressler 2000).

c) 12 dubious cases, such as humorous combinations created as puns. For example, Kim Possible in the game Kim Possible: Kimmunicator, an adventure game combining action and humour where players help the main character Kim using a Kimmunicator (Kim + communicator), a multipurpose communication device; and Viewtiful Joe (view + beautiful, a game where the main character, Joe, must save his girlfriend, who is trapped in a film). This group also comprises items which can be analysed either as headed or as coordinate, such as Toybot in the game Attack of the Toybots (Toybot can be both a toy and a robot, or a type of robot).

\subsection{Prototypical and central cases}

\subsubsection{Prototypes (38 items)}

This subsection describes the patterns displayed by prototypical cases arranged in order of frequency. Most prototypes were found to consist of two words that overlap at some common point and are both retained in the resulting blend: they are included in Mattiello's (2013) category of "overlapping blends". Overlapping blends exhibit "a phonological overlap of vowels, consonants or syllables between the constituents, with or without a proper shortening" (2013: 121), for example palimony (pal + alimony) and sexpert (sex + expert).

Therefore, the most frequent pattern registered in the corpus is word + word (19 items), as in Splatoon (splat + platoon), Nintendogs (Nintendo + dogs), and Carmageddon (car + Armageddon). In this pattern, both source words are retained and overlap at some common point. A particular subtype in this group includes words that overlap with other words and have the same (MediEvil: Medieval + evil) or nearly the same pronunciation as that of one of the source words, for example, Skullgirls (skull + schoolgirls); Raskulls (rascals + skulls); Runbow (run + rainbow, a game where players jump to defeat their enemies and overcome coloured obstacles); Elefunk (elephant + funk, 'funk' is slang for 'fear', a game where a herd of elephants must be rescued by building bridges); and Furmins (fur + vermins). These items can be regarded as cases of partial or discontinuous phonic overlap, which happens when "an overlapped segment shares some, but not all, of its component features" (Hong 2004: 131). In spite of this imperfect overlap, Mattiello (2013) includes these items as a subtype of overlapping blends.

Lehrer (2007) regards the MediEvil type as "orthographic blends" since the blend can only be processed as such when seen in writing. By contrast, in Rhythmvader (rhythm + invader), the constituents overlap phonologically but not orthographically, and the phonological overlap is discontinuous: there is an overlap of common / $/$ / which is interrupted by $/ \theta$ / from the source word 'rhythm', followed by an overlap of similar nasal phonemes of the source words: /m/ from 'rhythm' and /n/ from 'invader'. 
Other registered patterns with fewer instances are the following (in all cases there is partial graphic and/or phonic overlap):

a) Word + final splinter (with initial shortening). Examples: Gundemonium (gun + (pan)demonium), Starwhal (star + (nar)whal, a narwhal battle in space), and Gungeon (gun + (dun)geon, a game where players must use guns to defeat their enemies while descending through multiple floors). There is one case of phonic blending, where the constituents overlap phonologically but not orthographically: in Castlevania (castle + (Transyl)vania): there is discontinuous overlap of $/ \mathrm{s} /$ and $/ 1 /$, since $/ \mathrm{s} /$ is followed by /I/ in 'Transylvania'.

Another example of items combining a word and a final splinter is LocoCycle (loco + (motor)cycle, a vehicular combat videogame): the item keeps the number of syllables and stress pattern of 'motorcycle', and there is also the same syllabic structure of $<$ loco- $>$ and $<$ motor- $>$ in British English $(/ \mathrm{CV}-\mathrm{CV} /$ ) and overlap of vowel sounds: /'ləu kəu/, /'məu tə/. It is thus an overlapping blend with discontinuous overlap /Cəu $\mathrm{C} ə /$ and can join the subcategory of prototypes. It is worth noting, however, that in American English the overlap is reduced, since there is only a discontinuous overlap of the first vowel sound lou/.

Sometimes blending operates recursively. For example, cyborg is an established blend of cyb(ernetic) + org(anism), which is not prototypical in view of the type of shortening (two splinters with final shortening) and does not keep the prosodic trace of one of the sources in the shape of stress or number of syllables, but is still central due to medium integration (union of syllables: the new blend incorporates a syllable with the onset from one constituent and the rhyme from another) and a possible overlap of $/ \mathrm{r} /$ in American English. In the videogame title Spyborg (spy + (c)yborg) we come across recursive blending: the word 'spy' is combined with a final splinter of the blend cyborg in a prototypical blend displaying sound overlap.

b) Initial splinter + final splinter (final + initial shortening). Examples: Robocalypse (robo(t) + (apo)calypse), Octogeddon (octo(pus) + (Arma)geddon, a game where the player is a mutant octopus which destroys the world), Invizimals (invisi(ble) + (an)imals, a game where players capture invisible creatures using augmented reality and train them to fight), and $Q^{*} \operatorname{Bert}(\mathrm{Cube}(\mathrm{s})$ $+(\mathrm{H})$ ubert, an arcade game where the main character, $\mathrm{Q}^{*}$ bert, must hop from cube to cube avoiding enemies).

c) Initial splinter (with final shortening) + word. For example, Anarcute (anar(chy) + cute, a riot game. Note the overlapping /k/ sound), or Skelattack (skel(eton) + attack, a game in which an enchanted skeleton named Skully fights to protect his dungeon). In Skelattack there is a common overlapping /t/ from 'skeleton' and 'attack', and a possible overlapping /a/ from $<$-let- $>$ in 'skeleton' (which can be pronounced /lit/ or / lat/) and <at- $>$ in 'attack', which is pronounced/at/). One case of phonic blending (overlapping / $\mathrm{n} /$ ) is HarmoKnight (Harmo(ny) + Knight, a rhythm platform game with musical stages).

d) Discontinuous splinter + word. According to Mattiello (2013: 121), these items are included in the subclass of "intercalative blends", as described by Kemmer (2003). In the cases found in the corpus, a word or splinter is embedded in another source word, which thus becomes a discontinuous splinter. For 
example, Eufloria (a strategy game where players plant trees to colonize asteroids) fuses eu(phor)ia with the combining form ${ }^{8}$ flor ('flower'), from Spanish and earlier from Latin $f l \bar{s}$.

\subsubsection{Central but not prototypical cases ( 22 items)}

The following are examples of central cases registered in the corpus:

a) Items with high or medium integration (overlap or union) but weak prosodic trace (they only keep the primary stress of one of the sources, but not the number of syllables or any other features). Examples: Explodemon (explode + demon, a game where players control a character who can blow himself up to destroy enemies); Deathrow (death + throw, a sports videogame featuring a futuristic extreme sport); Creativerse (creative + universe); and Theatrhythm (theatre + rhythm). In Planescape (plane + escape) the constituents overlap orthographically but not phonologically.

b) Items with high integration (sound overlap) but an uncommon pattern of shortening, such as Frobot: (A)fro + robot, that is, a splinter with initial shortening (also a clipping) + word, where the semantic head 'robot' provides the stress pattern. In Picross (pi(cture) + cross(word)) there are two splinters with final shortening, and the item takes the stress pattern of 'picture' and shares the number of syllables of both sources.

c) Items with low integration (sound clustering) but still displaying various features of the prosodic trace of one of the sources, including syllable structure. The following are a few examples:

Beaterator (beat + (gen)erator, a music mixer) takes the number of syllables and stress pattern of 'generator' (the semantic head), and $<$ beat- $>$ and the replaced splinter $<$ gen- $>$ share the syllable structure CVC.

Miitopia (me $+(\mathrm{u})$ topia) takes the number of syllables and stress pattern of 'utopia' (the semantic head), and there is a common syllable structure CV in $/ \mathrm{mi} /<\mathrm{mii}->$ and $/ \mathrm{ju}: /<\mathrm{u}->$.

Toybot (toy + (ro)bot) keeps the number of syllables of 'robot' (which may function as the semantic head if the item is regarded as headed), the stress of both source words and the stress pattern of 'robot', and there is a common syllable structure CV in /tor/ and /rou/ (consonant + diphthong).

Wordament (word + (tourn)ament) keeps the number of syllables of 'tournament' (the semantic head), the stress of both sources and the stress pattern of 'tournament'. Besides, <word- $>$ and $<$ tourn- $>$ display the same syllable structure CVC with a long vowel sound (/w3:d/ and /t3:n/,/to:n/, or /tuən/). In American English, however, there is a graphic and phonic overlap of common /r/ (/w3:rd/ and/turn/, /to:rn/ or /t3:rn/), so the potential sound overlap and the strong prosodic trace could move the item closer to the subcategory of prototypes.

Lastly, in the coordinate blend Wizorb (wiz(ard) + orb) the constituents are clustered, but the item displays the stress and number of syllables of 'wizard', 
and the final constituent <-orb $>(/ \mathrm{o}: \mathrm{b} /)$ and the replaced splinter $<$-ard $>(/ \mathrm{ad} /)$ exhibit similarities as regards syllable structure $\mathrm{VC}$ and the voiced plosive quality of the consonant sounds. On these grounds, the item could be regarded as a central case. However, as happened in the case of Wordament above, in American English there would also be an overlap of /r/ in / $\mathrm{s}: \mathrm{rb} /$ and /ord/, which, together with the features of the prosodic trace, would bring the item closer to prototypes.

\subsection{Peripheral cases ( 20 items): complex clippings}

Blends can be regarded as "underlying compounds" (Lehrer 2007: 116) which undergo a simultaneous process of shortening and combining (Algeo 1991), so it can be posited that one of the neighbouring categories of blends is compounds. We can locate complex clippings as a marginal subcategory in the periphery of blends, proper clippings and compounds; for authors like Beliaeva (2014) for example, complex clippings or clipped compounds are a neighbouring morphological category with respect to blends, and in (2016: 23) she notes that blends and clipped compounds exemplify "a continuum of formations driven by two counteracting processes: compounding and clipping". Complex clippings can be said to form a multifarious network including instances which may also exhibit features of initialisms (such as capitalization or occasional maximum shortening to initial letters, as in Cospar / COSPAR: 'Co(mmittee on) Spa(ce) R(esearch)' or Satcoma: 'Sat(elite) Com(munications) A(gency)'). The categorial space of complex clippings can be conceived as an intersection area with neighbouring categories which leaves the door open to hybrids, that is, items of difficult ascription exhibiting features from different categories, such as JINTACCS: 'J(o)int Int(eroperability of) Tac(tical) C(ommand and) $\mathrm{C}$ (ontrol) S(ystem)'. The term 'complex clipping' has been chosen over other terms such as "clipped compounds" or "clipping compounds" (Bauer 2017: 158) since not all of them strictly originate from previously attested expanded compounds. These marginal items are represented in the corpus by a group of examples with the following features:

1. Two source words or three, as in MechWarrior (mechanized organism + warrior, mech or mecha being clippings of 'mechanized organism', a piloted robot), often forming a phrase.

2. Regarding spelling, occasionally both constituents are capitalized, which reinforces the independence of the constituents (SimCity) in the same way as hyphenation.

3. Low integration of the constituents, that is, clustering of syllables from different sources, and absence of phonic and/or graphic overlap.

4. As for the prosodic trace, the absence of features of the prosodic trace of one of the sources (typically the head in headed blends) makes the trace weaker and contributes to peripherality. Thus, Steambot keeps the stress of both sources ('steam' and 'robot') and the number of syllables and stress pattern of 'robot', but not the syllable structure CV of $<$ ro- $>$ or any similar sounds, which would make the prosodic trace stronger.

The peripheral item Magrunner (magnetic+ runner, an action game where players solve puzzles using MagTech, or magnetic technology, such as a glove 
that shoots opposite magnetic charges) keeps the stress of both sources and the stress pattern and number of syllables of 'magnetic', and there is a coincidence of syllable structure CVC between <-net> and <-runn> although completely dissimilar sounds, and the last syllables of 'magnetic' and 'runner' are also different. Besides, 'magnetic' is not the most prominent constituent in terms of position and meaning, since the semantic head is 'runner'.

5. Concerning shortening patterns, or the part of the constituents undergoing shortening, different combinations are registered:

a) Combinations also occurring in central blends:

a.1.) word + final splinter (only initial shortening). Examples: Apocalypsegeddon (apocalypse + (Arma)geddon), or Steambot (steam + (ro)bot).

a.2.) initial splinter + word (only final shortening). For example, Mecha$z o o$ (mecha(nized organism) + zoo); Infinifactory (infini(te) + factory, a game where a human abducted by aliens is forced to construct endless assembly lines to create objects); CivCity (Civ(ilization) + City, a city building strategy game including elements of the previous game Civilization); and SimAnimals (sim(ulation) + animals, a life simulation game where players interact with different species). Items tend to adopt the main stress of the remaining source word. Concerning Mechazoo, in view of the characteristics of the game, which evolves around robotic animals, the second constituent $(<-$ $\mathrm{zOO}>$ ) is not a shortened form of 'zoological garden', but rather the combining form meaning "animals" atypically used in final position (note that it is possible for the same combining form to be used initially or finally: phonograph, telephone).

b) Combinations that are not typical of central blends, which reinforces the peripherality of the items:

b.1.) word + initial splinter (only final shortening). Examples: SpaceChem (space + chem(istry), or AirMech (air + mech(anized organism)), a battle game where players control flying robots called AirMechs. The only feature of the prosodic trace of the source is that items tend to keep the primary stress of the first source word, but that word is not the semantic head.

b.2.) initial splinter + initial splinter (both with final shortening). Examples: Digimon, Pac-Pix. This combination is called "fragment blending" by Ronneberger-Sibold (2006), who describes it as a process in which "all blended lexemes are reduced to fragments mostly by clipping” (2006: 169), as in Cujasuma (Cuba + Java + Sumatra, a brand of tobacco).

Concerning Digimon (digi(tal) + mon(sters)), the item keeps the stress pattern and number of syllables of 'digital' (which is not the semantic head), but the syllable structure and the phonemes of the splinter $<$-mon $>(\mathrm{CVC})$ and the replaced splinter $<$-tal $>$ are different (in $<$-tal $>$ there is a consonant plus a syllabic consonant belonging to two different syllables).

Lastly, as regards Pac-Pix (Pac-(Man) + Pic(ture)s, where pix is the plural of pic (a clipping of picture in American English), it is a game 
where Pac-Man is drawn and controlled by means of drawings. PacPix keeps the stress pattern and number or syllables of 'Pac-Man' (which is not the semantic head) and some similarities concerning syllabic structure of the replaced constituent $<$-man $>$ and $<$ pix $>$ (CVC/CVCC) although no similar phonemes. Spelling reinforces constituent independence by means of hyphenation and capitals.

Finally, there is one item in the corpus which can be regarded as a complex clipping (a clipped phrase) on the borderline with initialisms: $X C O M$ or $X-C O M$ (Ex(traterrestrial) Com(bat Unit)). The item displays spelling in capitals and maximum graphic shortening of one constituent (the letter $X$ being a homophone of the syllable $<$ ex- $>$ ), the source words form a phrase (which is also a typical value of initialisms), and the pronunciation of the item includes a letter name, which is a typical feature of the pronunciation of alphabetisms.

\subsection{Graphic summary}

To close this section, Table 1 displays examples of prototypical, central and peripheral items of the category in accordance with their response to the defining parameters and values.

Table 1. Prototypical, central and peripheral items of the blend category in videogame titles.

\begin{tabular}{|l|c|c|c|c|c|c|}
\hline \multirow{2}{*}{$\begin{array}{c}\text { Items } \rightarrow \\
\text { Parameters }\end{array}$} & \multicolumn{2}{|c|}{ Prototypes } & Centre & \multicolumn{2}{c|}{ Periphery } & Borderline \\
\cline { 2 - 7 } & Carmageddon & Invizimals & Toybot & SimCity & Digimon & X-COM \\
\hline Source no. & 2 words & 2 words & 2 words & 2 words & 2 words & 3 words \\
\hline Source type & 1 phrase & 1 phrase & 1 phrase* & 1 phrase & 1 phrase & 1 phrase \\
\hline Pron'n & Orthoepic & Orthoepic & Orthoepic & Orthoepic & Orthoepic & $\begin{array}{c}\text { Letter name } \\
+ \text { orthoepic }\end{array}$ \\
\hline Spelling & $\begin{array}{c}\text { Mainly } \\
\text { lower case }\end{array}$ & $\begin{array}{c}\text { Mainly } \\
\text { lower case }\end{array}$ & $\begin{array}{c}\text { Mainly } \\
\text { lower case }\end{array}$ & $\begin{array}{c}\text { Capitals and } \\
\text { lower case }\end{array}$ & $\begin{array}{c}\text { Mainly } \\
\text { lower case }\end{array}$ & Capitals \\
\hline $\begin{array}{l}\text { Degree of } \\
\text { shortening }\end{array}$ & $\begin{array}{c}\text { Maximum }+ \\
\text { none or none }+ \\
\text { minimum }\end{array}$ & $\begin{array}{c}\text { Medium }+ \\
\text { medium }\end{array}$ & $\begin{array}{c}\text { None }+ \\
\text { medium }\end{array}$ & $\begin{array}{c}\text { Medium }+ \\
\text { none }\end{array}$ & $\begin{array}{c}\text { Medium + } \\
\text { medium }\end{array}$ & $\begin{array}{c}\text { Maximum }+ \\
\text { Medium }\end{array}$ \\
\hline $\begin{array}{l}\text { Phonic } \\
\text { integration }\end{array}$ & $\begin{array}{c}\text { High } \\
\text { (overlap) }\end{array}$ & $\begin{array}{c}\text { High } \\
\text { (overlap) }\end{array}$ & $\begin{array}{c}\text { Low } \\
\text { (clustering) }\end{array}$ & $\begin{array}{c}\text { Low } \\
\text { (clustering) }\end{array}$ & $\begin{array}{c}\text { Low } \\
\text { (clustering) }\end{array}$ & $\begin{array}{c}\text { Low } \\
\text { (clustering) }\end{array}$ \\
\hline $\begin{array}{l}\text { Shortening } \\
\text { pattern }\end{array}$ & $\begin{array}{c}\text { Word }+ \text { final } \\
\text { splinter or } \\
\text { initial splinter } \\
+ \text { word }\end{array}$ & $\begin{array}{c}\text { Initial } \\
+ \text { final } \\
\text { splinter }\end{array}$ & $\begin{array}{c}\text { Word + final } \\
\text { splinter }\end{array}$ & $\begin{array}{c}\text { Initial } \\
\text { splinter }+ \\
\text { word }\end{array}$ & $\begin{array}{c}\text { Initial } \\
\text { splinter } \\
+ \text { initial } \\
\text { splinter }\end{array}$ & $\begin{array}{c}\text { Initial } \\
\text { splinter } \\
+ \text { initial } \\
\text { splinter }\end{array}$ \\
\hline
\end{tabular}




\begin{tabular}{|c|c|c|c|c|c|c|}
\hline \multirow{2}{*}{$\begin{array}{c}\text { Items } \rightarrow \\
\text { Parameters } \downarrow\end{array}$} & \multicolumn{2}{|c|}{ Prototypes } & \multirow{2}{*}{$\begin{array}{l}\text { Centre } \\
\text { Toybot }\end{array}$} & \multicolumn{2}{|c|}{ Periphery } & Borderline \\
\hline & Carmageddon & Invizimals & & SimCity & Digimon & X-COM \\
\hline $\begin{array}{l}\text { Prosodic trace } \\
\text { of one source }\end{array}$ & $\begin{array}{l}\text { Length and } \\
\text { stress of head, } \\
\text { identical } \\
\text { overlapping } \\
\text { sounds /a:(r)/ }\end{array}$ & $\begin{array}{l}\text { Length } \\
\text { and stress } \\
\text { of non- } \\
\text { head, same } \\
\text { syllable } \\
\text { structure } \\
\text { CVC and } \\
\text { similar/ } \\
\text { identical } \\
\text { sounds } \\
\text { /bəl/məl/ }\end{array}$ & $\begin{array}{l}\text { Length and } \\
\text { stress of } \\
\text { head, same } \\
\text { syllable } \\
\text { structure CV } \\
\text { and similar } \\
\text { sounds } \\
\text { /tor/rəu/ }\end{array}$ & $\begin{array}{c}\text { Stress of } \\
\text { head }\end{array}$ & $\begin{array}{c}\text { Length and } \\
\text { stress of } \\
\text { non-head }\end{array}$ & No trace \\
\hline
\end{tabular}

* if the item is analysed as headed

As mentioned in subsection 2.1., it could be posited that the category has a polycentric structure - a development of radial categories that Kleiber (1990) describes as the "extended version" ("version étendue") of Prototype Theory. Therefore, central members with low integration (clustering) can act as a bridge for the assimilation of more peripheral items to the category (in this case, the marginal subgroup of complex clippings, which also displays connections with other neighbouring categories).

\section{Motivations}

The reasons for blend creation in the field of videogame titles were found to be essentially pragmatic, ludic, anticipatory, group-binding and artistic.

\subsection{Pragmatic aims}

Blends are new denominations for new entities which must be sold. The name is one way of introducing the game to potential buyers, and linguistic creativity intends to catch the buyer's eye with a view to selling the product.

The device of blending succeeds in economically (and simultaneously) capturing key features of the game to awaken the interest of potential buyers. In terms of cognitive linguistics, the formal process of blending is paralleled by a process of "conceptual blending" (Ungerer and Schmid 2006: 268) where "elements of two conceptual frames are blended" (Dirven and Verspoor 2004: 65). Besides, the structure of the blends of the corpus (which tend to keep entire source words or at least recognizable splinters) helps the quick and easy retrieval of the original constituents. Those cases where two words overlap and are both retained in the resulting blend (the most frequent subtype in the corpus) are cognitively advantageous because they allow the quickest retrieval and decodification. This statement agrees with the following suggestion made by Kaunisto (2000), who also analyses blend structure in terms of cognitive principles: 
the deletion of any items from the source words presents a certain amount of "danger" or "threat" as to the understandability of the final blend word. Ideal blends then would naturally be ones where the ending of the first source word and the beginning of the second source one overlap, resulting in a way in no deletion at all (Kaunisto 2000: para. 10).

Moreover, names that step out of the common rules of language or display unexpected or witty combinations (in the case of blends) catch the buyer's eye and are more easily remembered, thus becoming a marketing tool. In this respect, in her discussion of trendy blends, Lehrer (2003) points out that the speaker may feel proud to have decoded the new word, and this can generate positive attitudes towards the product and help him or her remember it with a view to buying that product:

when the hearer figures out the intended meaning, he or she is amused and perhaps feels clever for having 'gotten' the point. As a result, the hearer has a positive attitude toward the speech event and possibly toward the speaker and the referent of the neologism. If a positive attitude is created, this will reinforce the speaker's intention if the goal is for the hearer to remember the item (and maybe buy the product) (Lehrer 2003: 370).

This motivation is related to Ronneberger-Sibold's (2006) remark that "blending words (...) can simply serve to shroud an expression in mystery (...) in order to give the pleasure of solving a riddle to the hearer or reader" (2006: 161).

\subsection{Ludic aims}

Videogames have an inherent ludic quality and intend to provide interactive entertainment, and their names are also devised with ludic aims. Names play with the language, and the analysis of items belonging to this particular field evinces that all kinds of linguistic resources are used to call attention on the graphic and phonic shape of the words, for example, respelling (Toxikk, Yooka-Laylee, BloodRayne, Adrlft); homophone letters or numbers to replace words or parts of a word (Galak-Z, Left 4 Dead); rhyming (Blaster Master, Thrillville, Ape Escape); or word manufacture (Shadwen, Rinth Island). The creation of names is a field for play, wit and humour, as shown, for example, in the blend Hide and Shriek, which fuses the compound noun 'hide-and-seek' and the word 'shriek' to name a competitive horror game where players have to find and scare their opponents. Other humorous examples are Ed, Edd and Eddy: The Mis-Edventures, a team adventure game, or Pac'n Roll: Pac-(Man) + (rock)'n'roll, a game where players control Pac-Man, which rolls around different landscapes.

\subsection{Anticipatory or introductory aims}

Names anticipate features of the game and create expectations: an intriguing, humorous or witty name anticipates a puzzling, fun or creative game. Therefore, blends also anticipate the humorous, puzzling or creative qualities of the game they name and make them attractive. For example, Guacamelee (guacamole + melee), an action game where the player controls the Latin fighter Juan Aguacate (aguacate: 'avo- 
cado', a basic ingredient of guacamole), or Catlateral Damage (cat + collateral), a game where the player is a cat which knocks down the owner's belongings.

\subsection{Group-binding aims}

The interpretation of blends whose original constituents are not easily recoverable can contribute to reinforce group bonds and provide exclusivity, which become other motivations for blend creation. In this respect, blends can be used "to hide the sense of a message (...) which only the initiated will interpret correctly" (Ronneberger-Sibold 2006: 161). Therefore, for example, only gamers who are familiar with the notion of "mechs" ('mechanised organisms') will successfully decode Mechwarrior, Airmech or MechAssault, and gamers used to handling MagTech ("magnetic technology') will fully grasp the meaning of Magrunner.

\subsection{Artistic aims}

Videogames also have an artistic quality. Although the status of videogames as art forms is still controversial, the idea that at least some videogames have the potential to become art forms is becoming increasingly popular (Newman 2004; Smuts 2005; Clarke \& Mitchell 2007; Gil Juárez 2007; Chayka 2010; Melissinos 2015). Videogames are hybrid art forms produced in a digital age, since, as stated by Melissinos (2015: para. 2), they are "truly a collision of art and science. They include many forms of traditional artistic expression - sculpture in the form of 3D modelling, illustration, narrative arcs, and dynamic music - that combine to create something that transcends any one type". The aesthetic quality of videogames is also highlighted by Smuts (2005: para. 34): "modern video game designers are deeply concerned with traditional aesthetic considerations familiar to animators, novelists, set designers for theater productions and art directors for films".

Regarding language, as art forms, videogames are the product of creativity, and the language used to make up the denominations can also be creative. Resorting to lexical innovation in names implies that the name becomes an extension of the game as a form of art. In contrast with "conventional" blends such as brunch, which are more entrenched in the community, creative blends are perhaps more short-lived but also more open-ended as regards interpretation, and therefore more persuasive and eye-catching. Besides, creative names appeal to the players' fantasy, imagination and ability to explore, which are essential qualities for successful players. Videogame playing requires players to use exploration, creativity and imagination to work out the rules (Newman 2004), and the game titles extend this demand on the players' creativity and capability to explore by making the players work out the meaning of the blend when retrieving the sources, or by making them appreciate the word play the blend contains.

\section{Conclusion}

As shown in the different sections of this paper, the items compiled in the field of videogame titles support a centre-periphery structure for the category of blends, which is described by resorting to a multidimensional matrix of parameters and 
values. The category thus comprises prototypes and central cases (most of the items, in accordance with the features of prototypical categories), and peripheral and borderline cases, prototypes being the most frequent subgroup, as displayed in Table 2.

Table 2. Blends in videogame titles: types, number of items and percentages.

\begin{tabular}{|l|l|l|l|}
\hline \multicolumn{1}{|c|}{ Subcategory } & \multicolumn{1}{c|}{ Number of items } & \multicolumn{1}{c|}{ Percentage } & \multicolumn{1}{c|}{ TOTALS } \\
\hline $\begin{array}{l}\text { Prototypes (overlapping } \\
\text { blends) }\end{array}$ & 38 & $47.5 \%$ & $\begin{array}{l}\text { Prototypes and central } \\
\text { cases: 60 (75\%) }\end{array}$ \\
\hline Central cases & 22 & $27.5 \%$ & $\begin{array}{l}\text { Peripheral cases: } 20 \\
(25 \%)\end{array}$ \\
\hline $\begin{array}{l}\text { Peripheral cases } \\
\text { (complex clippings) }\end{array}$ & 20 & $25 \%$ & $\mathbf{8 0}(\mathbf{1 0 0 \% )}$ \\
\hline TOTALS & & \\
\hline
\end{tabular}

One obvious limitation of this study is the size of the corpus compiled. It is expected that the analysis of larger corpora of items belonging to other specific fields, such as film or advertising, could help refine the prototypical, central and peripheral areas of the category. Therefore, for example, the number and type of values displayed by subgroups of items would allow further structuration of the prototypical, central and peripheral areas.

It must be noted that, out of the 290 items of the main corpus of items exemplifying productive and creative word-formation in this particular field, the main device resorted to was compounding (124 items), followed by blending ( 80 items) and affixation (52 items). This preference for compounding (a process where both source words are retained) agrees with the trend observed in the analysis of the subcorpus of blends: all the prototypes and most of the blends in the corpus actually retain entire source words or at least recognizable splinters, which helps quick decodification. Besides, blending manages to capture key features of the game in an economical, creative and aesthetically attractive shape, with a view to making the product appealing to the eye and the ear, reinforcing group bonds in the decodification process, and of course having fun. Blends anticipate the humorous, puzzling or creative qualities of the game they name, reflect the challenge games contain and place the players at the heart of the action, in line with the features of videogames highlighted by Newman (2004: 16): "a videogame must provide exciting situations to experience, stimulating puzzles to engage with, and interesting environments to explore". This demand is extended to the titles when the players work out the meaning of the blend and the word play it contains. In conclusion, names resorting to lexical innovation devices such as blending wink at the players' creativity, imagination and ability to explore and work out the rules, and are an enticing preliminary to what they can expect to find in the game. 


\section{References}

\subsection{Main references}

Achard, Michel and Suzanne Kemmer, eds. (2004). Language, Culture and Mind. Stanford: CSLI Publications.

Algeo, John, ed. (1991). Fifty Years Among the New Words. Cambridge: C.U.P.

Bauer, Laurie (1988). Introducing Linguistic Morphology. Edinburgh: Edinburgh University Press.

Bauer, Laurie (2012). Blends: Core and Periphery. In Renner, Vincent, François Maniez and Pierre Arnaud, eds., 11-22.

Bauer, Laurie (2017). Compounds and Compounding. Cambridge Studies in Linguistics 155. Cambridge. C.U.P.

Beliaeva, Natalia (2014). A Study of English Blends. From Structure to Meaning and Back Again. Word Structure 7 (1): 29-54.

Beliaeva, Natalia (2016). Blends at the Intersection of Addition and Subtraction: Evidence from Processing. SKASE Journal of Theoretical Linguistics 13 (2): 23-45. URL: http:// www.skase.sk/Volumes/JTL32/pdf_doc/02.pdf

Berlin, Brent and Paul Kay (1969). Basic Colour Terms. Their Universality and Evolution. Berkeley: University of California Press.

Cannon, Garland (1986). Blends in English Word Formation. Linguistics 24 (4): 725753.

Chayka, Kyle (2010). Why Video Games are Works of Art. TheAtlantic.com, May 52010. URL: https://www.theatlantic.com/entertainment/archive/2010/05/why-video-gamesare-works-of-art/56205/

Clarke, Andy and Mitchell Grethe (2007). Videogames and Art. Bristol, UK: Intellect.

Cuyckens, Hubert, Thomas Berg, René Dirven and Klaus-Uwe Panther, eds. (2003). Motivation in Language: Studies in Honour of Günter Radden. Current Issues in Linguistic Theory 243. Amsterdam /Philadelphia: John Benjamins.

Dirven, René and Marjolijn Verspoor, eds. (2004). Cognitive Exploration of Language and Linguistics. Amsterdam /Philadelphia: John Benjamins.

Doleschal, Ursula and Anna M. Thornton, eds. (2000). Extragrammatical and Marginal Morphology. Munchen: Lincom Europa.

Dressler, Wolfgang U. (2000). Extragrammatical vs. Marginal Morphology. In Doleschal, Ursula and Anna M. Thornton, eds., 1-10.

Frasca, Gonzalo (2001). Videogames of the Oppressed. Videogames as a Means for Critical Thinking and Debate. Master's Thesis. Georgia Institute of Technology. URL: http:// www.ludology.org/articles/thesis/FrascaThesisVideogames.pdf

Gibbs, Raymond W. and Gerard J. Steen (1997). Metaphor in Cognitive Linguistics. Selected papers from the 5th International Cognitive Linguistics Conference, Amsterdam, July 1997. Amsterdam /Philadelphia: John Benjamins.

Gil Juárez, Adriana (2007). Los Videojuegos. Barcelona: U.O.C.

Gries, Stefan Th. (2004a). Isn't that Fantabulous? How Similarity Motivates Internal Morphological Blends in English. In Achard, Michel and Suzanne Kemmer, eds., 415-428.

Gries, Stefan Th. (2004b). Shouldn't it be Breakfunch? A Quantitative Analysis of Blend Structure in English. Linguistics 42 (3): 639-67.

Hong, Sung-Hoon (2004). Properties of English Word-blends: Structural Description and Statistical Distribution. English Language and Linguistics 18: 117-140. 
Kaunisto, Mark (2000). Relations and Proportions in the Formation of Blend Words. Paper presented at the Fourth Conference of the International Quantitative Linguistics Association (Qualico), Prague, August 24-26. URL: http://research.jyu.fi/kieliskooppi/ article/2013-11-Relations-and-Proportions-in-the-Structure-of-English-Blend-Words. html

Kelly, Michael H (1998). To ‘brunch' or to 'brench': Some Aspects of Blend Structure. Linguistics 36 (3): 579-590.

Kemmer, Suzanne (2003). Schemas and Lexical Blends. In Cuyckens, Hubert, Thomas Berg, René Dirven and Klaus-Uwe Panther, eds., 69-97.

Kleiber, Georges (1990). La Sémantique du Prototype. Catégories et Sens Lexical. Paris: Presses Universitaires de France.

Kövecses, Zoltan (2015). Where Metaphors Come from. Reconsidering Context in Metaphor. Oxford: O.U.P.

Lakoff, George (1987). Women, Fire and Dangerous Things. What Categories Reveal about the Mind. Chicago /London: University of Chicago Press.

Langacker, Ronald W. (1987). Foundations of Cognitive Grammar. Vol 1. Stanford: Stanford University Press.

Lehrer, Adrienne (1996). Identifying and Interpreting Blends: An Experimental Approach. Cognitive Linguistics 7 (4): 359-390.

Lehrer, Adrienne (2003). Understanding Trendy Neologisms. Rivista di Linguistica 15 (2): 371-384.

Lehrer, Adrienne (2007). Blendalicious. In Munat Judit, ed., 115-133.

López-Rúa, Paula (2000). English Acronyms and Alphabetisms: A Prototype-Based Approach with Special Reference to their Method of Formation, Realization, and Connections with other Morphological Devices. PhD Thesis. Santiago de Compostela: Universidad.

López-Rúa, Paula (2002). On the structure of Acronyms and Neighbouring Categories: A Prototype-Based Account. English Language and Linguistics 6 (1): 31-60.

López-Rúa, Paula (2003). Birds, Colours and Prepositions. The Theory of Categorization and Its Applications in Linguistics. LINCOM Studies in Theoretical Linguistics, Vol. 33. Munich: Lincom Europa.

López-Rúa, Paula (2004). The Categorial Continuum of English Blends. English Studies 85 (1): 63-76.

Mattiello, Elisa (2013). Extra-Grammatical Morphology in English. Abbreviations, Blends, Reduplicatives, and Related Phenomena. Topics in English Linguistics 82. Berlin /Boston: De Gruyter Mouton.

Melissinos, Chris (2005). Video Games are One of the Most Important Art Forms in History. Time Magazine, Sept. 22 2015. URL: http://time.com/collection-post/4038820/chrismelissinos-are-video-games-art/

Munat, Judit, ed. (2007). Lexical Creativity, Texts and Contexts. Amsterdam /Philadelphia: John Benjamins.

Newman, James (2004). Videogames. London /New York: Routledge.

Plag, Ingo (2003). Word-Formation in English. Cambridge: C.U.P.

Rosch, Eleanor (1978). Principles of Categorization. In Rosch, Eleanor and Barbara Bloom Lloyd, eds., 27-48.

Rosch, Eleanor and Barbara Bloom Lloyd, eds. (1978). Cognition and Categorization. Hove and London /Hillsdale, New Jersey : Lawrence Erlbaum.

Renner, Vincent, François Maniez and Pierre Arnaud, eds. (2912). Cross-Disciplinary Perspectives on Lexical Blending. Berlin /Boston: De Gruyter Mouton. 
Ronneberger-Sibold, Elke (2006). Lexical Blends: Functionally Tuning the Transparency of Complex Words. Folia Linguistica 40 (1-2): 155-182.

Smuts, Aaron (2005). Are Video Games Art? Contemporary Aesthetics 3. URL: https://www. contempaesthetics.org/newvolume/pages/article.php?articleID=299\&searchstr=smuts

Taylor, John R. (1995 /1989). Linguistic Categorisation. Prototypes in Linguistic Theory. Oxford: Clarendon Press.

Tejeiro Salguero, Ricardo and Manuel Pelegrina del Río (2003). Los Videojuegos. Qué son y cómo nos afectan. Barcelona: Ariel.

Tsohatzidis, Savas L., ed. (1990). Meanings and Prototypes. Studies in Linguistic Categorization. London /New York: Routledge.

Ungerer, Friedrich and Hans-Jörg Schmid. (2006). An Introduction to Cognitive Linguistics. $2^{\text {nd }}$ Edition. Harlow, England: Pearson Longman.

Wittgenstein, Ludwig (1989 /1953). Philosophical Investigations. Trans. by Gertrude Elizabeth Margaret Anscombe. Oxford: Blackwell.

\subsection{Electronic references used to compile the corpus}

Game Informer. URL: https://www.gameinformer.com/

Gamespot: Video Games Reviews and News. URL: https://www.gamespot.com/

Gaming History: Arcade, Video Games, Slots and More. URL: https://www.arcade-history. com

Metacritic. URL: https://www.metacritic.com/

Polygon. URL: https://www.polygon.com/

Steam. URL: https://store.steampowered.com/

The International Arcade Museum. URL: https://www.arcade-museum.com/

The Telegraph. URL: https://www.telegraph.co.uk/gaming/

VG24/7. URL: https://www.vg247.com 